\title{
A educação ambiental e as políticas educacionais: um estudo nas escolas públicas de Teresópolis (RJ)
}

Rodrigo de Azevedo C. Lamosa

Carlos Frederico B. Loureiro

Universidade Federal do Rio de Janeiro

\section{Resumo}

Este artigo tem como objeto a inserção da educação ambiental (EA) nas escolas públicas, utilizando como estudo de caso a rede municipal de Teresópolis (RJ). A EA crítica é o referencial teórico adotado, o qual permitiu compreender esse processo no ensino formal, em suas relações com as políticas públicas educacionais federais e municipais. No aspecto metodológico, a pesquisa foi desenvolvida inicialmente por meio da análise da Política Nacional de Educação Ambiental (PNEA) e dos documentos oficiais da educação da cidade. Em um segundo momento, priorizou-se o estudo dos projetos oficiais de EA da Secretaria Municipal de Educação e a pesquisa realizada diretamente nas escolas por meio da aplicação de um questionário construído com base em modelo utilizado pelo Ministério da Educação (MEC) em sua pesquisa "O que fazem as escolas que dizem que fazem educação ambiental?", realizada em 2006. Ao término do estudo, mesmo considerando a pertinência das iniciativas de professores e alunos no cotidiano escolar, as quais materializam práticas relevantes, foi possível concluir que questões fundamentais - currículo (diretrizes, arranjo e conteúdo), reorganização da carga horária docente (gestão escolar) e formação inicial e continuada de professores - ainda precisam ser contempladas pelas políticas públicas a fim do efetivo enraizamento da EA no contexto escolar.

\section{Palavras-chave}

Educação ambiental crítica - Política pública - Escola.

\section{Correspondência:}

Rodrigo de Azevedo C. Lamosa

Rua Almirante Tamandaré, 36, apto. 203

22210-060 - Rio de Janeiro/RJ

E-mail: rodrigo1281@yahoo.com.br 


\title{
Environmental education and education policies: a study in public schools of Teresópolis (RJ)
}

Rodrigo de Azevedo C. Lamosa

Carlos Frederico B. Loureiro

Federal University of Rio de Janeiro

\begin{abstract}
This article has as its object the insertion of environmental education (EE) in public schools, using as a case study the municipal school system of Teresópolis (RJ). Critical EE is the theoretical framework adopted, allowing the understanding of this process in formal education in its relations with federal and municipal public education policies. In methodological terms, the research was developed initially through the analysis of the National Policy for Environmental Education (PNEA) and of official EE documents for that town. At a second moment, the focus rested on the study of official EE projects of the Municipal Secretariat for Education, and on a research conducted directly at schools through the application of a questionnaire built on the basis of a model employed by the Ministry for Education (MEC) in its 2006 study entitled "What do schools that say they are doing Environmental Education do?". By the end of the study, even considering the pertinence of the initiatives by teachers and students in their school daily life, which materialized relevant practices, it was possible to conclude that fundamental questions - curriculum (guidelines, design, and content), reorganization of teaching workload (school management) and teacher initial and continued formation - still need to be addressed by public policies in order to process the effective rooting of EE within the school context.
\end{abstract}

\section{Keywords:}

Critical environmental education - Public policy - School.

Contact:

Rodrigo de Azevedo. C. Lamosa

Rua Almirante Tamandaré, 36, apto. 203

22210-060 - Rio de Janeiro/RJ

E-mail: rodrigo1281@yahoo.com.br 


\section{Introdução}

Este artigo apresenta os resultados de uma pesquisa que tem como objeto a inserção da educação ambiental (EA) nas escolas públicas e a relação entre esse processo e as políticas públicas educacionais de EA, em um movimento instituinte. Em termos metodológicos, adotou-se o estudo de caso (YIN, 2010), tendo sido as escolas municipais da cidade de Teresópolis, no Rio de Janeiro, escolhidas para a realização da pesquisa de campo.

A pesquisa foi realizada no período de agosto de 2008 a fevereiro de 2010 e teve como instrumento de coleta de dados um questionário baseado no instrumento que foi aplicado pelo Ministério da Educação (MEC), em pesquisa realizada em 2006 (BRASIL, 2006). A escolha do referido município justifica-se por ele ser local de trabalho ${ }^{1}$ de um dos pesquisadores autores do artigo e pelo fato de que suas escolas não foram incluídas no critério de escolha amostral, na referida pesquisa nacional do MEC. Os dados obtidos por meio da aplicação do questionário foram analisados e confrontados com os resultados da pesquisa federal, adotando-se como referencial teórico o conhecimento produzido por pesquisadores que atuam nesse novo campo de conhecimento, particularmente os que assumem a abordagem crítica (GUIMARÃES, 1995; LOUREIRO, 2004, 2008, 2009b; LOUREIRO; LAYRARGUES; CASTRO, 2009; QUINTAS, 2004; entre outros).

Neste trabalho, as questões orientadoras foram: quais são as principais dificuldades para inserir a EA nas escolas?; quais são os principais responsáveis por essa inserção?; como acontece a formação continuada dos professores responsáveis pela EA nas escolas?; como tais aspectos estão sendo trata-

1- A possibilidade de um professor de escola básica realizar pesquisa já suscitou um grande debate no meio acadêmico. Diversos trabalhos foram produzidos e apresentam aspectos norteadores para o desenvolvimento da pesquisa científica (LUDKE; CRUZ; BOING, 2009). dos pelas políticas públicas de EA do MEC, por meio da Coordenação Geral de Educação Ambiental (CGEA)?

Em termos metodológicos, a pesquisa foi desenvolvida, em um primeiro momento, por intermédio da análise da Política Nacional de Educação Ambiental (PNEA) ${ }^{2}$ e dos documentos oficiais da educação da cidade (documentos oriundos da I Conferência Municipal de Teresópolis e a Proposta de Implementação do Ensino Fundamental de Nove Anos na Rede Municipal de Teresópolis), e da leitura da bibliografia disponível sobre a inserção da EA no contexto escolar, à luz do referencial teórico crítico assumido. Em um segundo momento, a pesquisa priorizou o estudo dos projetos oficiais de EA da Secretaria Municipal de Educação, tanto da atual como da gestão anterior, e a aplicação do questionário junto aos educadores ambientais das escolas. A última fase da pesquisa resultou na sistematização dos dados e em sua leitura a partir da base teórica acumulada anteriormente.

A pesquisa nas escolas foi iniciada no mês de março de 2009. Os dados foram coletados com o objetivo de identificar a diversidade das práticas pedagógicas, os principais problemas, dificuldades e sujeitos envolvidos nessa inserção, abrangendo as 13 escolas do segundo segmento da rede municipal e outras 12 escolas do primeiro segmento, num total de 25 unidades escolares. Esse número de escolas representa 33\% da rede municipal.

0 questionário aplicado é formado por 23 perguntas. Destas, 13 são dicotômicas (questões em que só se pode escolher uma das opções), 7 são de múltipla escolha (é possível assinalar várias opções) e 2 são para ordenar prioridades (as três primeiras), além de 5 questões abertas.

Todas as escolas envolvidas foram escolhidas sem a interferência da Secretaria de Educação. 0 primeiro contato com elas deu-se por meio de uma reunião com os diretores,

2- Instituída pela Lei n $9.795 / 99$ e regulamentada pelo Decreto $n^{0}$ 4.281/02. 
na qual o projeto de pesquisa foi apresentado e o respondente ao questionário escolhido. Tal escolha foi feita pela direção das escolas, sendo um dos critérios, imputado pelo pesquisador de campo, a capacidade para responder pela EA da escola. 0 público respondente ao questionário-teste foi composto por diretores, orientadores pedagógicos e professores.

As políticas públicas são entendidas neste artigo como produto das disputas internas no Estado brasileiro. Tais disputas ocorrem entre grupos organizados na sociedade civil que procuram ocupar os espaços estratégicos na burocracia estatal, buscando a hegemonia no Estado ampliado ${ }^{3}$ (MATTOS, 1998). No caso da PNEA, não é diferente: o Ministério da Educação e o Ministério do Meio Ambiente, que formam o Órgão Gestor (OG) ${ }^{4}$, instância executiva da PNEA (1999-2010), são disputados por grupos com interesses e projetos divergentes. A ocupação do OG dá-se por meio dos postos na CGEA/MEC, no Departamento de Educação Ambiental do Ministério do Meio Ambiente (DEA/MMA), na Câmara Técnica, vinculada ao Conselho Nacional do Meio Ambiente, e no Comitê Assessor, formado por diversas instâncias da sociedade civil.

Entretanto, neste artigo, não se pretende analisar as disputas pela hegemonia ${ }^{5}$ da direção da PNEA, mas compreender a relação entre as políticas públicas educacionais e a inserção da EA nas escolas. Com isso, pretende-se apreender a diversidade de formas pelas quais a EA tem-se inserido nas escolas, bem como as dificuldades experimentadas pelos educadores, além de identificar os sujeitos envolvidos com

3- 0 conceito de Estado ampliado utilizado neste artigo foi desenvolvido por Antônio Gramsci. 0 Estado é, portanto, compreendido como uma relação social e histórica em que sociedade civil e sociedade política existem em relação permanente (BUCl-GLUCKSMANN, 1980).

4- A forma e o funcionamento do Órgão Gestor foram definidos pelo Decreto $n^{\circ} 4.281 / 02$.

5- Não há como considerar que haja, no movimento ambientalista ou no campo científico que se criou a partir da questão ambiental, um consenso que imobilize as disputas políticas presentes na sociedade capitalista. Considerando a teoria do Estado de Gramsci, é possível identificar como grupos articulam-se e buscam hegemonizar a EA. a gestão pública responsável pela EA, relacionando tais características às políticas públicas.

A partir dos resultados da pesquisa, concluiu-se que os problemas relativos à inserção da educação ambiental no espaço escolar e no sistema educacional exigem a compreensão dos contextos mais amplos e dos condicionantes econômicos e político-institucionais que situam os desafios da educação brasileira. Esse alerta é relevante, uma vez que se observam, nos diferentes eventos específicos da EA, relatos de experiências escolares e descrições de projetos e iniciativas, incluindo dificuldades cotidianas, sem que, contudo, nenhum desses aspectos seja relacionado aos condicionantes estruturais. Aqui se afırma claramente que a institucionalização e a universalização da EA nas escolas dependem, portanto, para além da motivação dos trabalhadores da educação e dos educandos, de políticas públicas e de recursos (fınanceiros e humanos), sem os quais não se garante sua efetiva incorporação ao currículo e à gestão escolar.

Cabe destacar, todavia, um importante elemento que esta pesquisa revela, em consonância com a pesquisa nacional do MEC. Identifica-se um movimento de crescente reconhecimento sobre a relevância da EA na última década, o qual se materializa nas práticas cotidianas de professores e alunos, e na diversidade identificada de iniciativas escolares, apesar da precariedade de recursos e dos demais problemas enfrentados pela educação no Brasil.

\section{Educação ambiental e as políticas públicas educacionais}

No Brasil, principalmente a partir da segunda metade dos anos 1990, foram elaboradas diversas políticas públicas com o objetivo de incentivar e promover a EA no ensino fundamental. Entre 2001 e 2003, o censo escolar feito pelo Instituto Nacional de Estudos e Pesquisas Educacionais Anísio Teixeira (INEP) inseriu uma pergunta sobre a presença 
da EA nas escolas brasileiras de ensino fundamental. Essa pergunta pretendia identificar as três modalidades previamente defınidas de inserção da EA na prática pedagógica: projetos, forma transversal nas disciplinas ou disciplina especial.

Segundo a pesquisa do censo escolar, a inserção da EA nas escolas públicas brasileiras teve um rápido crescimento entre os anos 2001 e 2004. Em 2001, 61,2\% das escolas declaravam inserir a EA em seu trabalho; já em 2004, esse percentual chegou a 94\%, com certa homogeneização regional, rompendo com os desequilíbrios anteriormente existentes (LIMA, 2007). A leitura desses dados permite afirmar que a prática da EA universalizou-se nos sistemas de ensino fundamental do país (TRAJBER; MENDONÇA, 2006).

No relatório "Um retrato da presença da educação ambiental no ensino fundamental brasileiro: o percurso de um processo acelerado de expansão", os autores afirmam:

Se fosse uma tarefa encontrar um fenômeno semelhante na história recente da educação formal brasileira, esta expansão somente poderia ser comparada aos significativos avanços obtidos na expansão do acesso ao ensino fundamental na segunda metade dos anos 90. Mais ainda, analisando a evolução da presença da EA, parece que esta reproduz a mesma evolução do ensino fundamental em termos da sua - praticamente total universalização. (VEIGA; AMORIM; BLANCO, 2005, p. 10)

Nesse relatório, algumas características da inserção da EA nas escolas puderam ser identificadas: a interação com a comunidade era realizada em apenas $8 \%$ do total de escolas; a queima de lixo era feita em 36\% das escolas em 2001 e em 41\% em 2004. Além do diagnóstico da universalização das práticas de EA escolar e da identificação de diversas contradições na rápida expansão destas, foi desenvolvido um índice com o objetivo de estabelecer uma hierarquia entre "os municípios mais providos de escolas em condições favoráveis para trabalharem com Educação Ambiental" (TRAJBER; MENDONÇA, 2006, pág. 13).

Os dados recolhidos a partir dos censos escolares (2001-2004) e sua posterior análise foram muito importantes, pois, como avaliou o grupo de trabalho (GT) de EA na $28^{\circ}$ Reunião da Associação Nacional de Pós-Graduação e Pesquisa em Educação (ANPEd,), realizada em 2005, representaram significativa inovação na avaliação das políticas públicas no Ministério da Educação. Entretanto, a partir desses indicadores quantitativos, novas questões foram levantadas no GT: mas que EA é praticada nas escolas?; quais são as práticas pedagógicas utilizadas pelas escolas para inserir a EA?; quais mudanças estão ocorrendo no cotidiano escolar em decorrência dessa inserção?; há um impacto significativo dessas práticas na comunidade?

Na tentativa de responder a essas questões, foi criado pela CGEA/MEC, em parceria com o Instituto de Estudos do Trabalho e Sociedades (IETS) e com as Universidades Federais do Mato Grosso do Sul (UFMS), do Rio de Janeiro (UFRJ), do Rio Grande (FURG), do Rio Grande do Norte (UFRN) e do Pará (UFPA), o projeto "O que fazem as escolas que dizem que fazem educação ambiental?” (TRAJBER; MENDONÇA, 2006).

Esse projeto ampliou a investigação por meio da pesquisa in loco, com o objetivo de conhecer como a escola praticava a educação ambiental. Foi possível revelar um diagnóstico do trabalho desenvolvido em 418 escolas do país, distribuídas nas cinco regiões. Embora não tenha ampliado seu objeto para outros municípios, a pesquisa teve a importância metodológica de elaborar um meio de investigação nas escolas, além de revelar um diagnóstico até então desconhecido, uma vez que se reconhece que há enorme precariedade de pesquisas com essa amplitude e voltadas para fornecer elementos que sirvam à priorização de ações em políticas 
públicas, sejam estas realizadas em programas de pós-graduação, em secretarias de educação ou no MEC.

Os resultados da pesquisa foram apresentados em 2006 na 29a Reunião da ANPEd. Nesse momento, o diagnóstico obtido deveria ser fundamental para a próxima etapa do projeto. A partir daí, ao projeto caberia:

Envolver de forma mais abrangente as universidades num trabalho mais focalizado, aprofundado, diversificado e mais qualitativo - além de iniciarmos um processo de construção de indicadores para a Educação Ambiental, envolvendo também a Diretoria de Educação Ambiental do Ministério do Meio Ambiente, que, com o MEC forma o Órgão Gestor da Política Nacional de Educação Ambiental. (TRAJBER; MENDONÇA, 2006, p. 14)

A continuidade da pesquisa era fundamental, pois, na etapa seguinte, haveria o aprofundamento de conhecimentos acerca de experiências selecionadas e o desenvolvimento dos mecanismos de avaliação das políticas públicas voltadas à inserção da educação ambiental nas escolas. Porém, o projeto não teve continuidade e as pesquisas não avançaram. Em função disso, os indicadores - por exemplo, o Índice de Desenvolvimento da Educação Ambiental (IDEA) - não passaram de uma proposta preliminar. A interrupção desse projeto é sintomática do desinteresse e das dificuldades da atual gestão de EA no MEC em promover políticas públicas voltadas para o conhecimento e para a estruturação da EA na instituição escolar por intermédio daquilo que é próprio do mundo da educação em seus espaços instituídos.

0 coordenador geral da pesquisa no âmbito das universidades nela envolvidas ressaltou algumas dessas questões fundamentais na reunião da ANPEd de 2006. São elas: currículo (diretrizes, arranjo e conteúdo), reorganização da carga horária docente (gestão escolar) e formação inicial e continuada de professores (LIMA, 2007; LOUREIRO; COSSÍO, 2007). Em 2010, tais questões continuam sendo fundamentais e demandam, por parte do MEC e das secretarias de educação, como prioridade nas políticas públicas educacionais, uma atuação efetiva em diálogo com os trabalhadores da educação, normalmente alijados dos processos decisórios em EA.

0 MEC, segundo posição do ex-diretor do DEA/MMA e da atual coordenadora da CGEA/ MEC, afirma possuir um programa nacional que articula diferentes esferas responsáveis pelo ensino fundamental no país; a CGEA afirma que tal característica é fundamental para a inserção da educação ambiental nas escolas. Nesse sentido,

0 programa do MEC propõe-se a construir um
processo permanente de educação ambiental
na escola. Por meio de modalidades de ensino
presenciais, à distância e difusas, as ações
envolvem secretarias de educação estaduais e
municipais, professores, alunos, comunidade
escolar, sociedade civil e universidade. (SOR-
RENTINO et al., 2005, p. 292)

0 programa do MEC elege duas prioridades: a escola, como espaço de construção permanente da EA, e a diversidade de atores envolvidos nas ações responsáveis pela inserção da EA nas escolas.

Ao dirigir a PNEA, ao lado do Ministério do Meio Ambiente e por meio do Órgão Gestor, o MEC tem responsabilidade pelas políticas públicas voltadas ao sistema educacional. Por isso, a eleição da escola como espaço prioritário das políticas para a inserção da EA é a opção correta. Entretanto, os gestores da PNEA admitem que esta deve inserir-se nas políticas públicas produzidas pelo MEC a partir de quatro ações indicadas problematicamente como estruturantes: Conferência Nacional de Meio Ambiente, Formação Continuada de Professores estudantes, Coletivos Jovens, Rede de Educação para a Diversidade ${ }^{6}$.

6-Ver em <http://portal.mec.gov.br/images/M_images/2009/sistemica.jpg>. 
Embora sejam iniciativas importantes, se dissociadas de outros aspectos identificados no relatório que sintetiza os resultados da pesquisa nacional coordenada pelo MEC (destacando que nessa lista está contemplada a formação), tornam-se ações que não atingem os problemas históricos da educação escolar brasileira e seus mecanismos de exclusão (GENTILI, 2008), condicionando a prática da EA. 0 diálogo pregado focaliza professores e alunos e nele não é citada nenhuma forma de organização coletiva destes. As organizações não governamentais (ONGs) e as empresas são postas na mesma posição, e movimentos sociais não são indicados. Com isso, fica-se no discurso de que há diálogo entre atores e consensos, sem considerar que estes não estão em condições iguais de participar e que têm interesses diferentes na tomada de decisão, o que afeta drasticamente o teor das políticas públicas, a capacidade de enfrentar conflitos e de estabelecer quais elementos são prioritários, tendo por premissa a defesa do interesse público e da universalização de direitos (LOUREIRO, 2009a). As diretrizes curriculares, que deveriam ter referência na realidade das escolas para, então, orientar as práticas dos educadores, não foram elaboradas até o presente momento. Em 2007, a CGEA chegou a anunciar, sem consequência, a convocação de uma consulta pública para produzir uma proposta de diretrizes curriculares para a EA, mas, até o início de 2010, nada havia sido apresentado. As intervenções da CGEA em fóruns deliberativos da educação, como conselhos e conferências nacionais, é tímida e não permite que os componentes da gestão escolar sejam repensados à luz das necessidades de incorporação da EA nas escolas.

Em sentido figurado, mas que ajuda na compreensão do efeito de tal estratégia adotada no MEC, é possivel afirmar que a EA relativa à escola torna-se um elemento que se movimenta em paralelo à educação instituída. Não consegue, desse modo, inserir-se como algo que a produza e a requalifique segundo as exigên- cias de materialização de uma escola pública democrática e capaz de contribuir na promoção de processos que superem as relações sociais destrutivas inerentes à sociedade capitalista (MÉSZÁROS, 2009).

\section{Educação ambiental e políticas públicas em Teresópolis}

A pesquisa considerou as políticas públicas produzidas pela Secretaria Municipal de Educação ao longo de dois governos (20052008 ( 2009-) de partidos diferentes. A opção por tomar as políticas das duas gestões mostrou-se correta diante do fato de as respostas ao questionário nas escolas terem considerado esse período. A maioria das escolas afirmou ter inserido a EA entre três e sete anos antes da realização da pesquisa.

A rede municipal de ensino de Teresópolis é formada por 75 escolas de ensino fundamental, das quais 62 oferecem o primeiro segmento de tal nível de ensino, enquanto 13 dispõem do segundo segmento. A maior parte, 43 escolas, está localizada na área urbana, estando as outras 32 localizadas na área rural. Além disso, a rede municipal é composta por 46 escolas que oferecem a pré-escola e 14 creches. Na cidade, existe uma população em idade escolar estimada em 34.615, alcançando 91,3\% de taxa de escolarização entre pessoas de 7 a 14 anos, e 33,2\% entre pessoas de 15 a17 anos 7 .

Entre 2005 e 2008, a EA inseriu-se na administração da Secretaria Municipal de Educação junto à Subsecretaria de Educação para o Campo. Nesse período, a proposta da Secretaria foi organizada no documento "Um novo olhar sobre a educação do campo”. Nele, diferentes ações foram previstas, das quais algumas chegaram a se desenvolver - como as palestras nas escolas e o concurso de hortas escolares - e outras não se materializaram. A capacitação de

7- Dados retirados do documento da Conferência Nacional de Educação (CONAE), etapa municipal - Teresópolis. Disponível em: <http://www. teresopolis.rj.gov.br/>. 
40\% do pessoal envolvido na educação do campo; a implantação de hortas escolares em 30\% das escolas de primeiro segmento; a criação de um laboratório de agroecologia em cada distrito da área rural, em escolas do segundo segmento, e de um laboratório móvel para atender às escolas, foram algumas das iniciativas previstas no documento da Secretaria que não chegaram até as escolas.

No primeiro ano do governo municipal eleito em 2009, a EA manteve-se atrelada à Subsecretaria de Educação para o Campo e passou a receber projetos federais, como o projeto "Hortas Escolares", por meio do MEC, e o projeto "Cenário Verde", do Parque Nacional da Serra dos Órgãos (PARNASO), unidade sob controle do Ministério do Meio Ambiente, por meio do Instituto Chico Mendes (ICMBio).

A educação ambiental nas políticas públicas educacionais dos dois governos caracterizou-se por uma grande quantidade de projetos desenvolvidos na rede. É possível traçar um histórico de projetos que foram realizados nas escolas da rede municipal nos últimos anos. Ao serem analisados de forma conjunta, percebe-se uma política de fomento de projetos, envolvendo atores diferentes na produção e na condução da inserção da EA nas escolas de Teresópolis.

Ao longo da pesquisa realizada nas escolas, foram identificados cinco projetos, criados por sujeitos que não pertencem à comunidade escolar. 0 projeto "Hortas Escolares", criado pelo MEC em parceria com a FAO (Organização das Nações Unidas para Agricultura e Alimentação), está presente em seis escolas da área rural da cidade; o projeto "Fazendo a Diferença", criado pela Indústria Comary de Bebidas, está presente em oito escolas; o projeto "Cenário Verde", criado pelo Parque Nacional da Serra dos Órgãos ${ }^{10}$, está presente nas 13 es-

8- Ver em <http://portal.mec.gov.br/index.php>.

9- Ver em <http://www.nossateresopolis.org.br/praticas_cidadas/ pc_002_fazendoadiferenca.html>.

10- Ver em <http://www.icmbio.gov.br/parnaso/index.php?id_menu=37>. colas do segundo segmento; o projeto "Consciência Ampla sobre Rodas" 11 , da empresa Ampla, concessionária de energia elétrica, esteve inserido em duas escolas.

A diversidade de sujeitos envolvidos nas experiências de EA nas escolas em Teresópolis corresponde à expectativa exposta pela CGEA. Entretanto, esses projetos ocorrem de forma dispersa, sem inserção nos projetos político-pedagógicos (PPP) das escolas (algumas sequer possuem PPP), ou garantias de sobrevivência nos anos posteriores. 0 resultado disso pode ser verificado na pesquisa empírica realizada nas escolas, em que os diretores acusaram as dificuldades em produzir planejamentos que considerem três anos letivos.

Tais projetos têm em comum o fato de não considerarem as questões fundamentais reivindicadas pela coordenação da pesquisa do MEC, na reunião da ANPEd de 2006. Um bom exemplo dos projetos é o "Cenário Verde", desenvolvido em 2009. 0 objetivo foi inserir as turmas de $6^{\circ}$ ano do ensino fundamental no projeto de visitação ao parque, envolvendo professores de história, ciências e geografia. No primeiro encontro, o projeto foi apresentado pelos coordenadores de EA da Secretaria Municipal de Educação e pelo coordenador do Parque Nacional. Nesse encontro, os professores receberam apostilas sobre as três disciplinas e sua relação com o tema do meio ambiente, nas normas dos Parâmetros Curriculares Nacionais (PCN), segundo consta no próprio material didático.

Entre as escolas pesquisadas, todas as 13 que oferecem o segundo segmento participaram do projeto, enviando turmas e professores para a visitação no parque. Com certeza, algumas dessas escolas, ao responderem o questionário, usaram a participação nesse projeto como uma forma de inserção da EA. Entretanto, o fato que ilustra a ausência de preocupação

11- Ver em <http://conscienciaampla.wordpress.com/tag/consciencia-ampla-sobre-rodas/>. 
do projeto com aquelas questões fundamentais ocorreu justamente na única escola que afirmou não fazer EA.

A escola com o maior Índice de Desenvolvimento da Educação Básica (IDEB) da rede municipal de Teresópolis foi projetada pelo arquiteto Oscar Niemeyer e doada à Secretaria de Educação da cidade por Adolfo Bloch, jornalista e dono da antiga Rede Manchete. Tal escola possui sete salas e apenas turmas do segundo segmento do ensino fundamental; é a escola da rede mais próxima do PARNASO, situando-se no mesmo bairro do parque. Como todas as demais escolas do segundo segmento, ela também participou do projeto "Cenário Verde". Apesar disso, quando se entrou em contato com o diretor da escola, este respondeu não haver EA naquela instituição. Mesmo assim, o pesquisador de campo foi até a escola e entrou em contato com a orientação pedagógica. 0 argumento era o mesmo. Apesar de os alunos terem visitado o parque, a atividade não havia tido nenhum reflexo no projeto político-pedagógico da escola. É necessário dizer que tais cargos são da confiança da Secretaria de Educação, e esse caso não se enquadraria em um boicote ao projeto “Cenário Verde”, tampouco à própria EA. Para confirmar isso, a orientação pedagógica da escola apresentou, no referido dia, um projeto de EA para 2010, feito pelas próprias orientadoras e em fase de discussão com os professores.

Nas escolas pesquisadas em Teresópolis, foi possivel encontrar professores e diretores esforçados e preocupados com a inserção da EA . Porém, tal esforço não é acompanhado por políticas de produção de materiais didáticos ou de formação continuada, embora o MEC afirme que as duas políticas sejam estruturantes da PNEA. Essa relação entre a política que se hegemonizou na condução da PNEA e as dificuldades enfrentadas pelos educadores nas escolas pôde ser medida na entrevista realizada junto a esses profissionais na cidade de Teresópolis.

A investigação acerca do tratamento dado à EA pelas políticas públicas educacio- nais considerou, por um lado, a política federal desenvolvida a partir da PNEA, focalizando as políticas decorrentes da CGEA/MEC. Por outro lado, a investigação tratou das políticas municipais. No município pesquisado, foi possível identificar que há uma continuidade no tratamento dado à EA pela secretaria dos dois governos, e que esse tratamento tem forte influência da direção dada à PNEA. Daí a ausência das questões fundamentais nos planos federais e municipais das políticas públicas educacionais, além da ênfase na política de projetos.

\section{Um estudo nas escolas municipais de Teresópolis}

Com exceção da escola de maior IDEB, todas as demais responderam ao questionário da pesquisa e seus dados serviram de base para a análise feita neste artigo.

0 crescimento acelerado que a EA teve no ensino fundamental brasileiro entre 2001 e 2004, período verificado pelo censo escolar, foi também identificado na pesquisa em Teresópolis. Entre as escolas pesquisadas, somente duas afırmaram trabalhar com a EA há mais de nove anos. Todas as demais escolas afirmaram ter inserido a EA nos últimos nove anos, sendo que 70\% o fizeram há menos de sete anos, e em $30 \%$ a inserção ocorreu há menos de um ano. 0 maior número de escolas afirmou ter introduzido o trabalho com a EA justamente no período em que ocorreu o censo escolar, entre três e sete anos antes da realização da pesquisa.

0 questionário formulado pelo INEP para a pesquisa organizada pelo MEC permite identificar as principais formas pelas quais a EA se inseriu nas escolas, sendo possível identificar mais de uma das opções: projetos, inserção curricular, disciplinas específicas ou projeto político-pedagógico (PPP). Segundo os dados divulgados pelo relatório final da pesquisa na região Sudeste, 79\% das escolas afirmam ter nos projetos o meio mais utilizado para trabalhar a EA. As demais modalidades - inserção curricular de 
disciplinas específicas e PPP - aparecem, respectivamente, com 55\% e 52\% (LIMA; VASCONCELLOS, 2007). Em Teresópolis, essa tendência permaneceu: a maioria dos respondentes $(76 \%)$ afirmou serem os projetos os meios mais utilizados para inserir a EA no contexto escolar. A segunda opção mais utilizada foi a inserção por meio do PPP (40\%), e a terceira, a inserção por meio de tema transversal (25\%).

0 meio mais utilizado para o trabalho com a EA nas escolas é o projeto, tendência essa identificada na região Sudeste e confirmada em Teresópolis. Os projetos possuem algumas características importantes que merecem destaque. A maioria das escolas (92\%) respondeu que os projetos de EA ocorrem pela integração entre duas ou mais disciplinas, e que um tema gerador é escolhido para ser trabalhado nas disciplinas (70\%). Isso demonstra que a inserção da EA nas escolas ocorre de forma intimamente ligada às disciplinas escolares.

Nos PCN, a recomendação é que a EA seja inserida nas escolas de forma interdisciplinar e transversal. Entretanto, o texto do tema transversal meio ambiente enfatiza o caráter conscientizador da EA, numa perspectiva de mudança dos costumes, sem apresentar diretrizes para essa forma de inserção. Assim, a defesa da interdisciplinaridade presente nos PCN não consegue superar a visão idealista proporcionada por uma filosofia do sujeito, na expectativa de superar a compartimentalização dos conhecimentos (LIMA, 2007; JANTSCH; BIANCHETTI, 2004).

Ao pesquisar sobre a iniciativa da realização dos projetos, foi possível identificar que a maioria das escolas (85\%) assinalou que o grupo de professores é responsável por tal movimento. Outro aspecto possível de ser apreendido na pesquisa foi a participação das empresas nos projetos de EA nas escolas. A iniciativa da realização desses projetos é das empresas em quase a metade (46\%) das escolas entrevistadas. A entrada das empresas e das ONGs nas escolas, por meio da EA, não é contraditória à PNEA. No capítulo II, seção I, da lei que instituiu a PNEA ( $n^{\circ}$ 9.795/99), esse aspecto é destacado:

Art. $7^{\circ}$. A Política Nacional de Educação Ambiental envolve em sua esfera de ação, além dos órgãos e entidades integrantes do Sistema Nacional de Meio Ambiente - Sisnama, instituições educacionais públicas e privadas dos sistemas de ensino, os órgãos públicos da União, dos Estados, do Distrito Federal e dos Municípios, e organizações não-governamentais com atuação em educação ambiental.

Os projetos pesquisados envolvem diversos atores, incluindo as secretarias municipais e estaduais de educação e meio ambiente, como também empresas e ONGs, além do PARNASO. Outros projetos são produzidos pelas próprias escolas, resultado do trabalho docente e da orientação pedagógica. As universidades não aparecem nos projetos de EA nas escolas. Ao responderem o questionário, todas as escolas foram unânimes em afirmar que não têm nenhuma relação com a universidade. Na cidade de Teresópolis, não existe nenhuma instituição de ensino superior pública, havendo apenas algumas instituições privadas que não mantêm relação com as escolas municipais.

Entre as questões fundamentais levantadas por Loureiro (2004, 2008, 2009a, 2009b), duas têm relação direta com o problema da atuação das escolas na formação continuada dos professores: a reorganização da carga horária docente (gestão escolar) e a formação inicial e continuada. No questionário respondido nas escolas, dez perguntas tentavam apreender esse assunto.

Nas questões relativas à atuação das escolas na formação dos professores em EA, poucas instituições afirmaram destinar carga horária para esse fim. A liberação de carga horária para a formação em EA (16\%), a ajuda de custo para a formação continuada (15\%) e 
a promoção de grupos de estudos na unidade escolar (15\%) foram citadas por poucas escolas, enquanto a liberação para cursos de extensão ou de pós-graduação não foi assinalada por nenhuma delas. Outro dado negativo relaciona-se à aquisição e distribuição de material didático-pedagógico: a metade das escolas afirmou não ter acesso a esse material.

$\mathrm{Na}$ pesquisa em uma escola localizada na área rural de Teresópolis, a respondente escreveu uma observação no questionário: "a liberação para a formação continuada dos professores não depende da unidade escolar"; para que ocorram encontros entre grupos de professores, é preciso "ter disponibilidade de horários". Por fim, completou: "a maior parte dos tópicos acima, para que possa ser colocada em prática, depende da Secretaria Municipal de Educação (SME), em parceria com a escola".

Os professores que se esforçam para inserir a EA nas escolas da rede municipal deparam com problemas de falta de tempo para o estudo, baixos salários que exigem mais trabalho e menos estudo, além da inexistência dos recursos didáticos. Entretanto, as escolas e os professores são criticados. As escolas são caracterizadas, no documento da Secretaria Municipal de Educação, como espaço de reprodução da cultura da repetência:

Pedagogicamente, a repetência é baseada em uma série de premissas equivocadas como é o caso da cultura instalada nas escolas que o estudante que não aprendeu, ou não apreendeu o suficiente, aprenderá se tomar exatamente o mesmo caminho pela segunda vez - o caminho que o fez fracassar a primeira vez; que nada foi apreendido ao longo do processo e que, portanto, é necessário começar tudo de novo desde o início; que o conhecimento e a aprendizagem operam em uma dimensão linear, seguem rotas fixas e são o resultado do exercício repetitivo. (TERESÓPOLIS, 2009, p. 3)
Nas escolas pesquisadas, foi identificado que, ao contrário do que é afirmado no documento, existe uma intensa luta para incorporar novos processos pedagógicos, com a inserção da própria EA. Esse esforço produzido pelos educadores ocorre mesmo diante da falta de apoio das políticas públicas. No mesmo documento, os professores são criticados pela inapetência didática e pela falta de conhecimento:

Em ambos os casos observamos que a repetência está vinculada a problemas no manejo de classe, na inadequação da didática e da metodologia de ensino, tanto nas turmas de alfabetização infantil quanto nas turmas do $6^{\circ}$ ano de escolaridade, ou seja, o desconhecimento por parte do professorado dos processos de aprendizagem do alunado, principalmente desta faixa etária. (p. 4)

Essa descrição dos professores da rede não foi confirmada pela pesquisa realizada nas escolas. Além de tê-los identificado como os principais responsáveis pela iniciativa de projetos nas escolas, a presença de professores qualificados, com formação superior e especializados, foi o segundo fator mais importante para a inserção da EA nas escolas. Um número grande de escolas (76\%) apontou esse fator.

Embora a qualificação dos professores seja um importante elemento explicativo para a inserção da EA nas escolas em Teresópolis, a ausência de políticas públicas destinadas à formação continuada não permite que este seja o fator determinante. Na rede municipal, existe outro problema: a inexistência de um plano de carreira que estimule a formação dos servidores. Tal plano poderia ter sido debatido durante a etapa municipal da Conferência Nacional de Educação (CONAE), realizada em 2010, na qual o pesquisador foi conferencista e delegado. Porém, a Secretaria Municipal de Educação retirou da pauta a formulação do plano de carreira e organizou uma comissão para redigir uma proposta, ainda não apresentada. 
0 fator que mais contribui para a inserção da EA nas escolas de Teresópolis, segundo a unanimidade dos respondentes, é a presença de professores idealistas que atuam como lideranças. Esses professores são responsáveis pela elaboração de projetos a partir dos saberes conquistados ao longo de sua formação e no próprio trabalho docente. Independentemente dos possiveis erros, o trabalho de tais professores precisa ser valorizado para que, apoiados pela formação continuada, possam incluir a EA no projeto político-pedagógico das escolas, tornando-a independente de lideranças eventuais.

Em relação às dificuldades enfrentadas para a inclusão da EA nas escolas, cerca de $50 \%$ dos professores apontam a precariedade de recursos materiais e humanos, bem como a falta de previsão de tempo para planejamento e realização de atividades extracurriculares como os principais problemas a serem enfrentados. Esse diagnóstico também foi incluído, no relatório da pesquisa nacional, entre as ações que deveriam ser priorizadas pelos responsáveis pela implantação da PNEA.

\section{Consideraçōes finais}

A realidade encontrada nas escolas de Teresópolis registra a existência de professores que têm participação fundamental na inserção da EA no contexto escolar e que não podem ser alvos da crítica fácil feita por pesquisadores e gestores da educação, que responsabilizam tais trabalhadores por possíveis fragilidades nas iniciativas sem considerar as determinações sociais que conformam a escola pública no país. Entretanto, também foi identificado que esses trabalhadores estão diante de políticas públicas que não priorizam o espaço escolar, nem a resolução dos problemas de sua realidade.

A escolha do quadro teórico e conceitual marxista permitiu realizar uma análise crítica do processo de inserção da EA no ensino fundamental e as consequentes implicações para o trabalho docente nas escolas públicas. Neste estudo, tal pensamento foi fundamental para identificar como a ideologia dominante opera no âmbito da ação teórica e prática da EA, ao deslocar discursivamente as condições de trabalho das práticas cotidianas e pessoais, legitimando estratégias de EA organizadas no plano governamental sem uma profunda vinculação com as políticas educacionais em curso e os rumos do desenvolvimento nacional.

A formulação da EA crítica exige, portanto, o restabelecimento dos vínculos, tantas vezes esquecidos e, por vezes, rejeitados, entre educação e trabalho. 0 problema de romper com esses vínculos é apreender a realidade de forma dual, sob o risco de imputarmos a ela uma ordem construída idealmente. A realidade estabelece-se em um processo contraditório, uno na diversidade, concretizando-se de forma complementar, mas também antagônica, em constante movimento. A EA crítica deve ser entendida como um ato intencional e democrático, devendo servir ao propósito da emancipação humana. $\mathrm{Na}$ atualidade, a tarefa mais importante aos educadores críticos, particularmente no que se refere à questão ambiental, é apreender as formas de operação ideológica do capital na educação e como estas estabelecem hegemonias que fazem da prática educativa um instrumento central de reprodução de um capitalismo visto como verde, fundado na naturalização das relações de mercado.

Pautada nesse referencial teórico e em diálogo com a empiria, a pesquisa realizada nas escolas foi fundamental para esclarecer alguns aspectos. 0 primeiro é que as principais dificuldades enfrentadas pelos educadores na inserção da EA nas escolas não estão sendo resolvidas pelas priorizações dadas no âmbito da PNEA. Outra importante conclusão diz respeito à necessidade de compreensão dos problemas da educação brasileira em sua relação com o processo acelerado de inserção da EA no ensino fundamental. Sem esse movimento, corre-se o risco de repetir a crítica aos professores e 
à escola - sem as mediações exigidas - pelo fracasso de algumas tentativas de transversalização, integração curricular e inserção no projeto político-pedagógico. Um terceiro aspecto a destacar remete ao fato de que, apesar de o Órgão Gestor afirmar ter na formação continuada dos professores um dos eixos estruturantes da PNEA, a investigação feita nas escolas municipais de Teresópolis demonstra quão longe está o sucesso dessa política em sua reduzida efetividade de aplicação junto às redes municipais.

Concomitantemente, a interrupção do trabalho que visava estruturar políticas públicas voltadas para a escola, iniciado em 2006 com a pesquisa " 0 que fazem as escolas que dizem que fazem educação ambiental?” - a qual entraria, em seguida, na fase da construção de indicadores para a avaliação das políticas públicas e a atuação focada nas prioridades identificadas (gestão escolar, currículo e formação inicial e continuada) -, é um fato grave a ser considerado. Sua ocorrência levou à inexistência de um diagnóstico nacional atualizado que permitisse balizar ações e estabelecer prioridades institucionais a partir de informações precisas que expressassem a realidade escolar brasileira, e de um diálogo mais próximo com os trabalhadores da educação, em suas formas organizadas, nos espaços deliberativos do sistema educacional.

A pesquisa aqui apresentada indicou, portanto, que a direção dada às políticas públicas de EA no âmbito escolar não contribui para a resolução das principais dificuldades enfrentadas pelos educadores das redes públicas municipais, particularmente a de Teresópolis. As políticas que priorizam o desempenho e a mobilização em torno da EA, seja pelas conferências que não são deliberativas ou por meio de projetos e iniciativas de parceria, sem políticas públicas construídas no contexto das políticas educacionais mais amplas e em articulação com os trabalhadores da educação, não acompanham as reais necessidades demandadas pelas escolas públicas do país.

\section{Referências}

BRASIL. Ministério da Educação. Secretaria de Educação Continuada, Alfabetização e Diversidade. Educação na diversidade: 0 que fazem as escolas que dizem que fazem educação ambiental? Brasília: MEC/SECAD, 2006. (Coleção Educação para Todos, Série Avaliação, n. 6).

BRASIL. Presidência da República (Casa Civil). Lei n 9.795, de 27 de abril de 1999. Dispõe sobre a educação ambiental, institui a Política Nacional de Educação Ambiental e dá outras providências. Disponível em: <http://portal.mec.gov.br/secad/arquivos/pdf/ educacaoambiental/lei9795.pdfa>. Acesso em: jan. 2009.

BUCI-GLUCKSMANN, C. Gramsci e o estado. Rio de Janeiro: Paz e Terra, 1980.

GENTILI, P. (Org.). Pedagogia da exclusão: crítica ao neoliberalismo em educação. 15. ed. Petrópolis: Vozes, 2008.

GUIMARÃES, M. A dimensão ambiental na educação. Campinas: Papirus, 1995.

INDÚSTRIA BRASILEIRA DE BEBIDAS COMARY. Projeto fazendo a diferença. Rio de Janeiro, 2008.

JANTSCH, A. P.; BIANCHETTI, L. (Orgs.). Interdisciplinaridade: para além da filosofia do sujeito. 7. ed. Petrópolis: Vozes, 2004.

LIMA, M. J. G. S. 0 que fazem as escolas que fazem educação ambiental no Rio de Janeiro? In: REUNIÃO ANUAL DA ANPED: 30 ANOS DE PESQUISA E COMPROMISSO SOCIAL, 30., 2007, Caxambu. Anais... Caxambu, 2007. CD-ROM.

LIMA, M. J. G. S.; VASCONCELLOS, M. M. N. A educação ambiental como disciplina escolar: explicitando a tensão entre teoria e prática. In: ENCONTRO DE PESQUISA EM EDUCAÇÃO AMBIENTAL, 4., 2007, Rio Claro. Anais... Rio Claro: UNESP, 2007. CD-ROM. 
LOUREIRO, C. F. B. Educação ambiental transformadora. In: LAYRARGUES, P. P. (Org.) Identidades da educação ambiental brasileira. Brasília: MMA/DEA, 2004. p. 65-84.

. Educação ambiental e "teorias críticas". In: GUIMARÃES, M. (Org.) Caminhos da educação ambiental: da forma à ação. 3. ed. Campinas: Papirus, 2008. p. 51-86.

. Mundialização do capital, sustentabilidade democrática e políticas públicas: problematizando os caminhos da educação ambiental. Ambiente e Educação, Rio Grande, v. 14, 2009a.

Trajetórias e fundamentos da educação ambiental. 3. ed. São Paulo: Cortez, 2009b.

LOUREIRO, C. F. B.; COSSÍO, M. F. B. Um olhar sobre a educação ambiental nas escolas: considerações iniciais sobre os resultados do projeto "O que fazem as escolas que dizem que fazem educação ambiental". In: MELLO, S.; TRAJBER, R. (Orgs.) Vamos cuidar do Brasil: conceitos e práticas em educação ambiental. Brasília: MEC/UNESCO, 2007. p. 57-64.

LOUREIRO, C. F. B.; LAYRARGUES, P. P.; CASTRO, R. S. (Orgs.). Repensar a educação ambiental: um olhar crítico. São Paulo: Cortez, 2009.

LUDKE, M.; CRUZ, G.; BOING, L. A. A pesquisa do professor da educação básica em questão. Revista Brasileira de Educação, v. 14, n. 42, set./dez. 2009.

MATTOS, M. B. História: pensar e fazer. Rio de Janeiro: Laboratório Dimensões da História, 1998.

MÉSZÁROS, I. Estrutura social e formas de consciência: a determinação social do método. São Paulo: Boitempo, 2009.

QUINTAS, J. S. Educação no processo de gestão ambiental: uma proposta de educação ambiental transformadora e emancipatória. In: LAYRARGUES, P. P. (Org.). Identidades da educação ambiental brasileira. Brasília: DEA/MMA, 2004. p. 113-140.

SORRENTINO, M. et al. Educação ambiental como política pública. Educação e Pesquisa, São Paulo, v. 31, n. 2, p. 285-299, mai./ago. 2005.

TERESÓPOLIS. Secretaria Municipal de Educação. Proposta de implementação do ensino fundamental de nove anos na rede municipal de Teresópolis. Teresópolis, 2009.

TRAJBER, R.; MENDONÇA, P. (Orgs.). Educação na diversidade: 0 que fazem as escolas que dizem que fazem educação ambiental. Brasília: Secretaria de Educação Continuada, Alfabetização e Diversidade, 2006.

VEIGA, A.; AMORIM, E.; BLANCO, M. Um retrato da presença da educação ambiental no ensino fundamental brasileiro: 0 percurso de um processo acelerado de expansão. Brasília: Instituto Nacional de Estudos e Pesquisas Educacionais Anísio Teixeira, 2005.

YIN, R. K. Estudo de caso: planejamento e método. 4. ed. Porto Alegre: Bookman, 2010.

Recebido em 22.04.10

Aprovado em 20.11.10

Rodrigo A. C. Lamosa é mestre e doutorando pelo Programa de Pós-Graduação em Educação da Universidade Federal do Rio de Janeiro e membro do Laboratório de Investigação em Educação, Ambiente e Sociedade (LIEAS).

Carlos Frederico B. Loureiro é professor dos Programas de Pós-Graduação em Educação e em Psicossociologia de Comunidades e Ecologia Social da Universidade Federal do Rio de Janeiro, coordenador do Laboratório de Investigações em Educação, Ambiente e Sociedade (LIEAS) e pesquisador CNPq. E-mail: floureiro@openlink.com.br. 